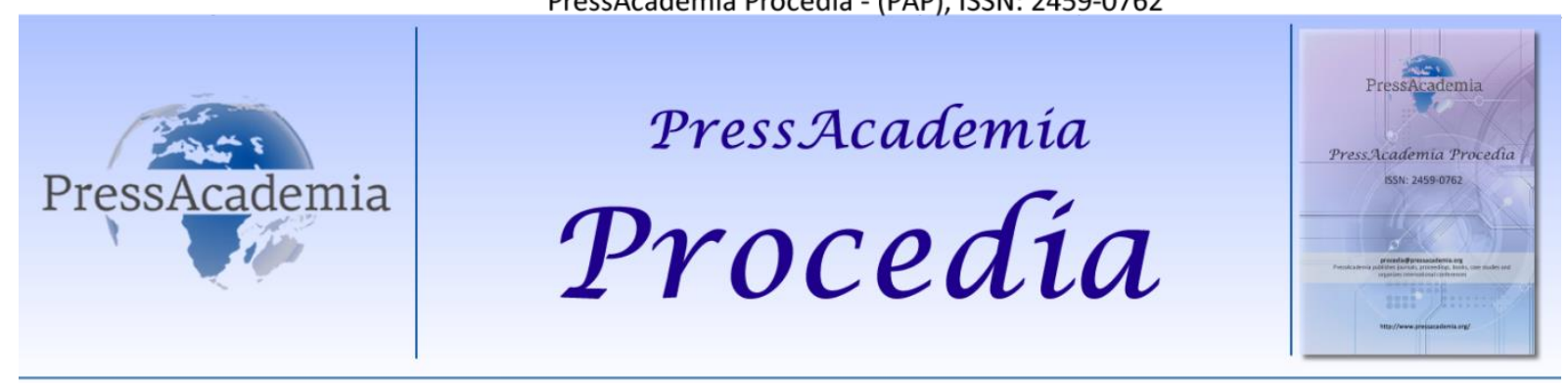

2nd World Conference on Technology, Innovation and Entrepreneurship

May 12-14, 2017, Istanbul, Turkey. Edited by Sefer Şener

\title{
COMPARATIVE STUDY ON THORIUM (IV) SORPTION ONTO SODIC BENTONITE AND MAGNETIC BENTONITE
}

\author{
DOI: 10.17261/Pressacademia.2017.602 \\ PAP-WCTIE-V.5-2017(40)-p.286-292
}

\section{Mohamed A. Didi, Abdelkader Miraoui}

Laboratory of Separation and Purification Technologies, Department of Chemistry, Tlemcen University, Algeria. madidi13@yahoo.fr

\section{ABSTRACT}

In this paper, the liquid-solid extraction of Thorium (IV) is made by Sodic bentonite and Magnetic bentonite. Magnetic adsorbent can be quickly separated from a medium by a simple magnetic process, in view of these properties; some parameters were studied to assess the performance of maghemite nanocomposite clay for the removal of Thorium ions. The operating variables studied are initial La(III) concentration, $\mathrm{pH}$, ionic strength, temperature and contact time. The time needed for magnetic bentonite to adsorb the maximum of Th (IV) is 45 minutes and 60 minutes for sodic bentonite. For magnetic bentonite, optimal extraction yield was achieved in a initial pH equal at 6.2 and for sodic bentonite, the variation of initial pH has no influence on the extraction yield. The sorption capacities of sodic bentonite and magnetic bentonite are 41.24 and $31.34 \mathrm{mg} \cdot \mathrm{g}^{-1}$ respectively. Adsorption equilibrium data were calculated for Langmuir and Freundlich isotherms. It was found that the sorption of Th (IV) on sodic and magnetic bentonite was better suited to the Langmuir adsorption model. Thermodynamics data leads to endothermic and spontaneous process for magnetic bentonite and exothermal for sodic bentonite. The quantitative elution study of Thorium can be realized with acetic acid for sodic bentonite and sulfuric acid for magnetic bentonite.
\end{abstract}

Keywords: Bentonite, nanoparticle, isother, thorium, process

\section{INTRODUCTION}

Like all heavy metal, thorium exhibits harmful character for nature and human health. Thorium toxicity is similar as that of uranium [1-3].

The presence of thorium in wastewaters could be hazardous for human health. That is why thorium removal from aqueous effluents still remains a major issue to be addressed. A brief overview of the wide literature produced in this regard reveals the use of solvent extraction with various commercial extractants, liquid membrane and ion exchange resins $[4,5]$.

The extraction of Thorium is performed by $\gamma-\mathrm{Fe}_{2} \mathrm{O}_{3}$ enriched with bentonite clay and sodic bentonite, the objectives of this study are to assess the performance of maghemite nanocomposite clay for the removal of Thorium ions. Effects of $\mathrm{pH}$ and temperature on the adsorption process are also investigated. The adsorption capacity has been studied using the adsorption isotherm technique. Various isotherm equations are used to determine the best isotherm equation which represents the experimental data adequately and satisfactorily. The kinetic adsorption is also studied and tested using different models. Further studies can explore the possible regeneration of nanocomposite clay for reuse.

\section{EXPERIMENTAL}

\subsection{Reagents}

Thorium solution at $10^{-2} \mathrm{M}$ was prepared by dissolving of Th $\left(\mathrm{NO}_{3}\right)_{4} .4 \mathrm{H}_{2} \mathrm{O}$ (from FLUKA) $(0.552 \mathrm{~g})$ in $100 \mathrm{~mL}$ of distilled water. The initial $\mathrm{pH}$ of the sample solutions were adjusted by using dilutes $\mathrm{HNO}_{3}$ or $\mathrm{NaOH}$ (from Sigma-Aldrich). $\mathrm{NaNO}_{3}$ (from Merck), $\mathrm{C}_{2} \mathrm{H}_{3} \mathrm{NaO}_{2}$ and $\mathrm{NaS}_{2} \mathrm{O}_{3}$ were used in the salt effect. Arsenazo III $10^{-3} \mathrm{M}$ (from Fluka) was prepared by dissolving $0.0820 \mathrm{~g}$ in absolute ethanol. Hydrochloric acid (from Organics), sulfuric acid (from Fluka), nitric acid (from Cheminova), and acetic acid (from Riedel Dehaen) were used from elution study. 
The natural bentonite used in this study was obtained from deposits in the area of Maghnia, Algeria. For magnetic nanoparticles synthetized, $\mathrm{FeCl}_{2} \cdot 4 \mathrm{H}_{2} \mathrm{O}, \mathrm{FeCl}_{3} \cdot 6 \mathrm{H}_{2} \mathrm{O}, \mathrm{NH}_{4} \mathrm{OH}, \mathrm{HNO}_{3}$ and $\mathrm{Fe}\left(\mathrm{NO}_{3}\right)_{2}$ were used.

\subsection{Apparatus}

The extraction of Th (IV) was studied by the batch process using a stirring vibrator (Haier model). pH measurements were performed with a pH meter using a combined electrode mark (Adwa). A magnet and centrifugation for the recovery of the magnetic particles and sodic bentonite, respectively, in the aqueous phase were used. Samples containing Th (IV) were analyzed by spectrophotometer (Analytik Jena Specord 210 Plus) with Arsenazolll as ligand.

\subsection{Preparation of Magnetic Particles}

The ferrofluid magnetic used was the maghemite $\left(\gamma-\mathrm{Fe}_{2} \mathrm{O}_{3}\right)$ nanoparticles dispersed in an aqueous solution. Particles were synthesized by coprecipitation of a stoichiometric mixture of ferrous and ferric chloride in an ammonium hydroxide solution. The precipitate magnetite $\left(\mathrm{Fe}_{3} \mathrm{O}_{4}\right)$ obtained was acidified by nitric acid and oxidized into maghemite $\left(\nu-\mathrm{Fe}_{2} \mathrm{O}_{3}\right)$ at $90^{\circ} \mathrm{C}$ with iron (III) nitrate. The maghemite particles obtained were precipitated by the acetone, then dispersed into water leading to an ionic ferrofluid acid $(\mathrm{pH}=2.0)$. After these step, nanoparticles were positively charged, with nitrate as counter ions.

\subsection{Preparation of Magnetic Bentonite}

The composites can be prepared by the following procedure:

Dissolve $\mathrm{FeCl}_{3}(7.8 \mathrm{~g}, 28 \mathrm{mmol})$ and $\mathrm{FeSO}_{4}(3.9 \mathrm{~g}, 14 \mathrm{mmol})$ in $400 \mathrm{~mL}$ solution at $70^{\circ} \mathrm{C}$. Add the clay bentonite at $3.3,6.6$ or $9.9 \mathrm{~g}$ in order to obtain the following adsorbent: iron oxide weight ratios 1:1, 1.5:1 and 2:1. To this suspension add a solution of $\mathrm{NaOH}\left(100 \mathrm{~mL}, 5 \mathrm{~mol} \mathrm{~L}^{-1}\right)$ drop wise to precipitate the iron oxides. Wash the obtained solid materials with distilled water and dry in an oven at $100^{\circ} \mathrm{C}$ for $2 \mathrm{~h}$. After the preparation a simple test with a magnet $(0.3 \mathrm{~T})$ can be carried out showing that the whole material is completely attracted to the magnet.

\subsection{Extraction and Analysis Procedure}

The method of extraction used for this study, was carried out by a mixture of $4 \mathrm{~mL}$ of Th(IV) solution of known concentration, and $0.01 \mathrm{~g}$ of our solid adsorbent (bentonite mineral and magnetic bentonite) in Erlenmeyer with stopper, under vigorous stirring. Both liquid and solid phases were separated by centrifugation for bentonite mineral and magnet for magnetic bentonite, the solid phase will be regenerated for other applications and the liquid phase was measured by the UV-visible spectrometer. The sample of Th (IV) was analyzed by a mixture of $100 \mu \mathrm{L}$ Arsenazolll and $100 \mu \mathrm{L}$ of Th (IV) in a medium $\mathrm{HCl} 9 \mathrm{M}(2 \mathrm{~mL})$. The interaction of Arsenazo (III) with Th (IV) can be estimated at $\lambda_{\max }=660 \mathrm{~nm}$.

The percentage of Thorium ions that was extracted by solids extractant was determined as (Eq. 1):

Extraction $\%=\frac{C i-C e}{C i} * 100$

The amount of Thorium uptakes at time $\mathrm{t}$, qt $\left(\mathrm{mg} \mathrm{g}^{-1}\right)$, was calculated by Eq. 2:

$q t\left(\frac{\mathrm{mg}}{\mathrm{g}}\right)=\frac{(C i-C t)}{W} . V . M$

where $C_{i}, C_{t}$ and $C_{e}$ are the initial, time $t$ and equilibrium Th (IV) concentration ( $\mathrm{mol} \mathrm{L}^{-1}$ ), respectively, $V(4 \mathrm{~mL})$ is the volume of the solution, $\mathrm{M}$ molecular weight ( $\left.\mathrm{g} \mathrm{mol}^{-1} 1\right)$, and $\mathrm{w}$ is the mass of the solids adsorbents $(0.01 \mathrm{~g})$.

\section{RESULTS AND DISCUSSION}

In this study different parameters are examined: contact time, effect of initial $\mathrm{pH}$, initial concentration of Thorium, the effect of ionic strength.

\subsection{Effect of Time Contact}

The equilibrium time is the necessary and sufficient time to reach the equilibrium exchange of Th (IV) between the aqueous phase and the adsorbents. To perform this effect, we will fix the concentration initial of Thorium $\left(10^{-4} \mathrm{~mol} \mathrm{~L}^{-1}\right)$, values of initial $\mathrm{pH}$, and adsorbents amount $(0.01 \mathrm{~g})$. Figure 1 illustrate the extraction yield as a function of time, where the extraction efficiency increases rapidly with increasing of time. The time needed for magnetic bentonite to adsorb the maximum of Th (IV) is 45 minutes $\left(58 \%, 8.26 \mathrm{mg}^{-1} \mathrm{~g}^{-1}\right)$ and 60 minutes for sodic bentonite $\left(89 \%, 8.65 \mathrm{mg} \cdot \mathrm{g}^{-1}\right)$. 
Fig. 1: Removal of thorium by magnetic and sodic bentonites as a function of time
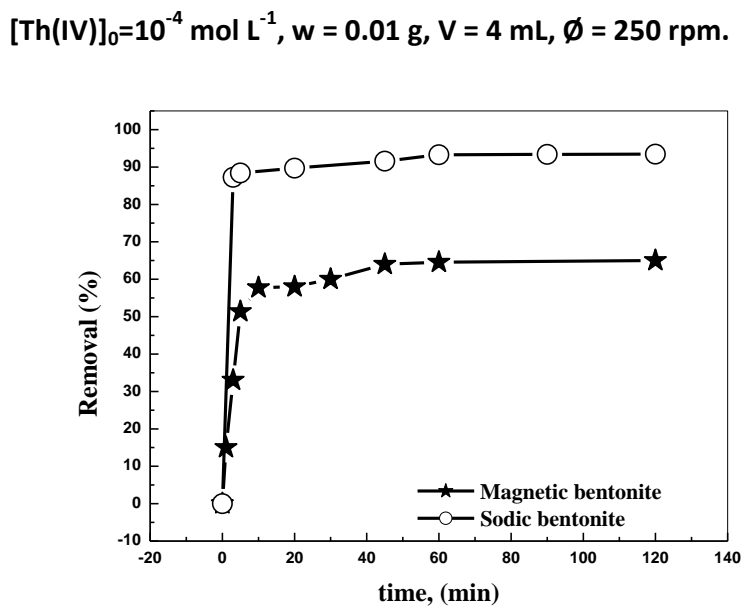

\subsection{Effect of $\mathrm{pH}$}

Sorption of thorium by magnetic bentonite and sodic bentonite were studied at different $\mathrm{pH}$ value ranged from 1,43 to 9,35 and the results are show in Figure 2, it is seen that the extraction yield is very low and stable in acidic region and the removal of thorium begins to increase with increase in $\mathrm{pH}$ and remains maximum in the $\mathrm{pH} 6,36$. With further increase in $\mathrm{pH}$, the sorption efficiency decreases. This observation could be explained as follows: At pH in the range of 1.45.1 , hydrogen ions compete strongly with metal thorium (IV) ions for the active sites, which results in less metal sorption. When solution $\mathrm{pH}$ is from 2.0 to 4.5, the competing effect of hydrogen ions decreases, instead, thorium (IV) ions sorption increases. When pH is 6.2, a large number of active adsorption sites are released, and the maximum number of adsorption sites are obtained, which provide lots of opportunities for thorium (IV) ions attack, so there are the maximum thorium(IV) sorption efficiency at the $\mathrm{pH}$ values 6.2. Beyond $\mathrm{pH} 6.2$, insoluble thorium hydroxide started precipitating, which led to low thorium (IV) ions sorption efficiency at equilibrium. By against the variation initial pH of the stock solution of thorium, has no influence on the extraction yield for sodic bentonite, which is between $80 \%$ and $85 \%$.

Fig. 2: Removal of thorium by magnetic and sodic bentonites as a function of initial pH.

$$
[\mathrm{Th}(\mathrm{IV})]_{0}=10^{-4} \mathrm{~mol} \mathrm{~L}^{-1}, \mathrm{w}=0.01 \mathrm{~g}, \mathrm{~V}=4 \mathrm{~mL}, \emptyset=250 \mathrm{rpm} \text {. }
$$

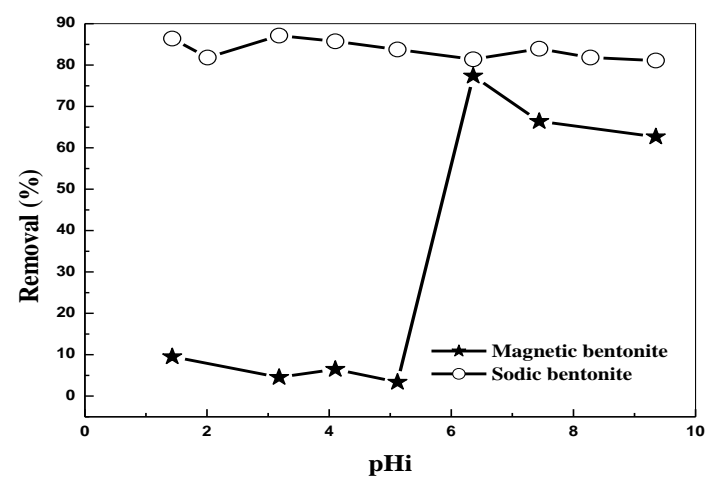

\subsection{Effect of Initial Metal Concentration}

Several experiments were also undertaken to study the effect of varying the initial thorium concentration on uptake (q) from the solution by $0.01 \mathrm{~g}$ of our adsorbent. The amount of Th(IV) sorbed per unit mass of the particles magnetic increased with the initial metal concentration. 
Fig. 3: Removal of thorium by magnetic and sodic bentonites as a function of [Th(IV)].

$\mathrm{w}=0.01 \mathrm{~g}, \mathrm{~V}=4 \mathrm{~mL}, \varnothing=250 \mathrm{rpm}$.

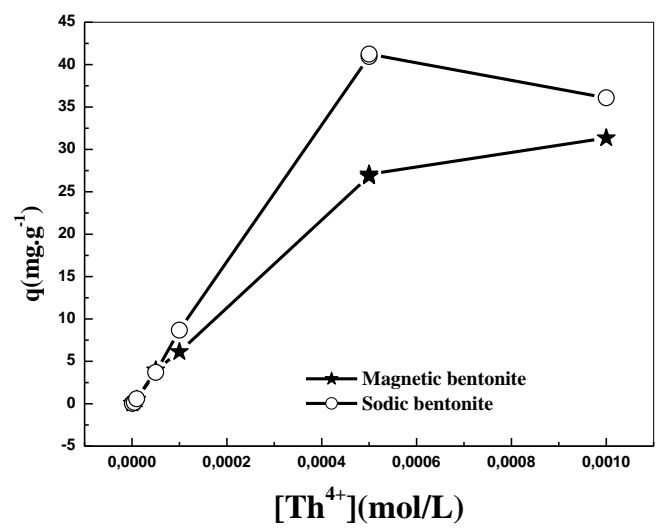

Figure 3 show that the maximum sorption capacities for the metal ions were $41.24 \mathrm{mg} \cdot \mathrm{g}^{-1}\left(0.177 \mathrm{mmolg}^{-1}\right)$ for sodic bentonite and $31.34 \mathrm{mg} \cdot \mathrm{g}^{-1}\left(0.135 \mathrm{mmolg}^{-1}\right)$ for magnetic bentonite, this values indicate that sodic bentonite and magnetic bentonite were effectives sorbents in treatment of diluted thorium solutions.

\subsection{Isotherm Adsorption}

The sorption data, commonly known as adsorption isotherms, are basic requirements for the design of adsorption systems. Classical adsorption models, Langmuir and Freundlich, were used to describe the equilibrium between adsorbed Th (IV) ions on the sodic and magnetic bentonite site.

In this concentration range, the Langmuir isotherm correlated better than Freundlich isotherm (Table 1) with the experimental data from adsorption equilibrium of thorium ions by magnetic bentonite and sodic bentonite, suggested a monolayer adsorption. The maximum adsorption values were in accordance with the values obtained experimentally (Table $1)$.

Fig. 4: Langmuir isotherm plot for the sorption of Th(IV) onto sodic

and magnetic bentonite, $w=0.01 \mathrm{~g}, \mathrm{~V}=4 \mathrm{~mL}, \emptyset=250 \mathrm{rpm}$.

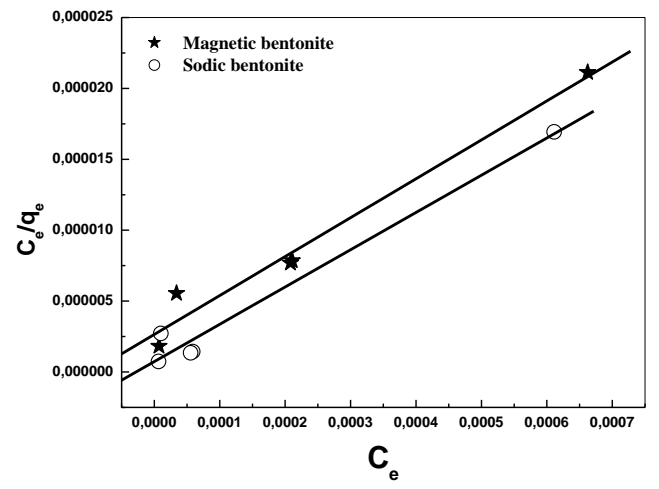


Fig. 5: Freundlich isotherm plot for the sorption of Th(IV)

onto sodic and magnetic bentonite, $w=0.01 \mathrm{~g}, \mathrm{~V}=4 \mathrm{~mL}, \emptyset=250 \mathrm{rpm}$.

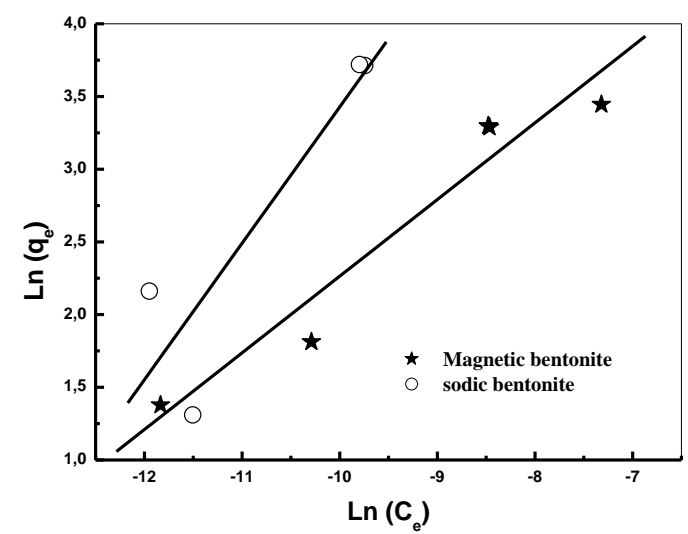

Table 1: Isotherm models parameters for the adsorption of Th(IV)

on magnetic bentonite and sodic bentonite

\begin{tabular}{|c|c|c|c|}
\hline & $\begin{array}{l}q_{m}(\exp .), \\
m g . g^{-1}\end{array}$ & Langmuir isotherm & Freundlich isotherm \\
\hline Sodic bentonite & 41.24 & $\begin{array}{l}\mathrm{R}=0.9883 \\
\mathrm{q}_{\mathrm{m}}(\text { calc. })=38,03 \mathrm{mg} \cdot \mathrm{g}^{-1} \\
\mathrm{~K}_{\mathrm{L}}=9927.7\end{array}$ & $\begin{array}{l}R=0,8983 \\
K_{F}=362217,44 \\
n=0,9380\end{array}$ \\
\hline Magnetic bentonite & 31.34 & $\begin{array}{l}\mathrm{R}=0.9863 \\
\mathrm{q}_{\mathrm{m}}(\text { calc. })=36.44 \mathrm{mg} \cdot \mathrm{g}^{-1} \\
\mathrm{~K}_{\mathrm{L}}=10362.69\end{array}$ & $\begin{array}{l}R=0,9663 \\
K_{F}=1881,83 \\
n=0,527\end{array}$ \\
\hline
\end{tabular}

\subsection{Effect of Temperature and Thermodynamic Parameters}

The effect of temperature on the sorption of thorium from nitrate solution by sodic bentonite and magnetic benonite at $\mathrm{pH} 6.2, \mathrm{~V}=4 \mathrm{~mL}, \mathrm{w}=0.010 \mathrm{~g}, \varnothing=250 \mathrm{rpm}$ and concentration Th(IV) $10^{-4} \mathrm{~mol} \mathrm{~L}^{-1}$ is studied. This study is efficient for the determination of thermodynamic data such as, the Gibbs free energy change $(\Delta \mathrm{G})$, enthalpy change $(\Delta \mathrm{H})$ and entropy change $(\Delta S) . \Delta G$ is calculated using the following equations:

$\Delta \mathrm{G}=\Delta \mathrm{H}-\mathrm{T} \Delta \mathrm{S}$

$\Delta G=-R T \operatorname{LnD}$

where $\mathrm{R}$ is the gas constant $\left(8.314 \mathrm{~J} \mathrm{~mol}^{-1} \mathrm{~K}^{-1}\right)$, and $\mathrm{T}$ the temperature $(\mathrm{K})$.

Figure 6 shows removal percent (\%) of thorium ion onto sodic bentonite and magnetic bentonite as a function of the temperature. It can be seen that the yield extraction of Th (IV) increases with increasing temperature for magnetic bentonite, this behaviour indicates that thorium sorption onto magnetic bentonite is an endothermic and spontaneous process, as supported by the positive values of $\Delta \mathrm{H}$ and $\Delta \mathrm{S}$ (Table 2); decrease in $\Delta \mathrm{G}$ values with increase in temperature showed that the sorption was most favourable at higher temperature. In contrast, increasing temperature from 25 to $50^{\circ} \mathrm{C}$ was found to have a detrimental effect on the extraction process for sodic bentonite, the negative value of $\Delta \mathrm{H}$ indicate that the extraction process is exothermal. 
Fig. 6: Removal of thorium by magnetic and sodic bentonites as a function of temperature. $[\mathrm{Th}(\mathrm{IV})]_{0}=10^{-4} \mathrm{~mol} \mathrm{~L}^{-1}, \mathrm{w}=0.01 \mathrm{~g}, \mathrm{~V}=4 \mathrm{~mL}, \varnothing=250 \mathrm{rpm}$.

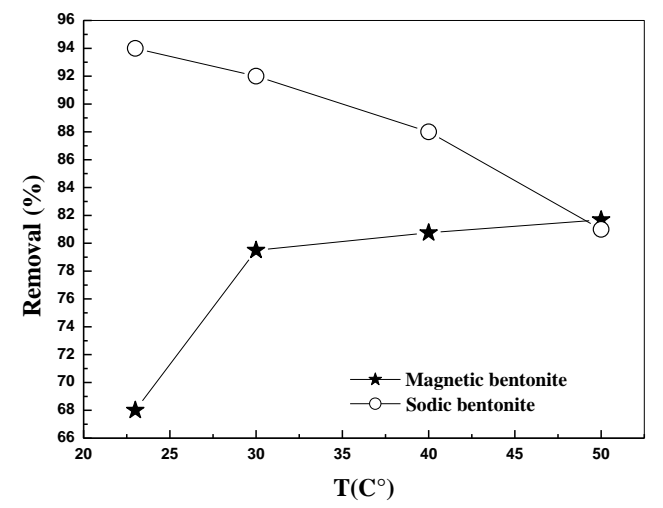

Fig. 7: Plot of Eq. 6 for the thorium sorption on by magnetic and sodic bentonites, $[\mathrm{Th}(\mathrm{IV})]_{0}=10^{-4} \mathrm{~mol} \mathrm{~L}^{-1}, \mathrm{w}=0.01 \mathrm{~g}, \mathrm{~V}=4 \mathrm{~mL}, \varnothing=250 \mathrm{rpm}$.



Table 2: Thermodynamic parameters for the sorption of Th(IV) on sodic and magnetic bentonite

\begin{tabular}{lcclccc}
\hline Bentonite & $\Delta \mathrm{H}\left(\mathrm{kJ} \cdot \mathrm{mol}^{-1}\right)$ & $\Delta \mathrm{S}(\mathrm{J} / \mathrm{K})$ & \multicolumn{3}{l}{$\Delta \mathrm{G}(\mathrm{kJ} / \mathrm{mol})$} & \\
\cline { 3 - 6 } & & & $\mathrm{T}=296 \mathrm{~K}$ & $\mathrm{~T}=303 \mathrm{~K}$ & $\mathrm{~T}=313 \mathrm{~K}$ & $\mathrm{~T}=323 \mathrm{~K}$ \\
\hline Sodic bentonite & $-38,138$ & $-55,78$ & $-21,62$ & $-21,23$ & $-20,67$ & $-20,11$ \\
Magnetic bentonite & 5,699 & 79,897 & $-17,962$ & $-18,52$ & $-19,32$ & $-20,12$ \\
\hline
\end{tabular}

\section{CONCLUSION}

In this paper, Liquid-solid extraction of Thorium (IV) is made by sodic bentonite and magnetic bentonite. The extraction efficiency was determined as a function of various parameters such as time, initial $\mathrm{pH}$, Thorium concentration and temperature. The experimental capacity obtained was $31.34 \mathrm{mg} \cdot \mathrm{g}^{-1}$ for magnetic bentonite and $41.24 \mathrm{mg} \cdot \mathrm{g}^{-1}$ for sodic bentonite. The sorption of Th (IV) achieves equilibration at 45 minutes and 60 minutes for magnetic bentonite and sodic bentonite, respectively. Optimal extraction yield was achieved in a initial pH equal at 6.2 for magnetic bentonite, By against, the variation of initial $\mathrm{pH}$ has no influence on the extraction yield.

The results obtained in this study are very close and there is not a big difference, but magnetic bentonite have a unique superiority in separation, it can be quickly separated from a medium by a simple magnetic process, in view of this properties and by the results obtained in this study, magnetic bentonite can be a promising material for sorption, 
immobilization and pre-concentration of rare earth elements, radioactive metal and heavy metal ions from large volume of solutions.

\section{REFERENCES}

1. Ishikawa Y, Wada I, Fukumoto M (2001). J Environ Pathol Toxicol Oncol 20(4): 311-315.

2. Martling U, Mattsson A,Travis L B, Holm L E, Hall P (1999). Radiat Res 151: 293-299.

3. VanKaick G, Bahner M L, Liebermann Deta I (1999). Radiologe 39(8): 643-651.

4. Tavlarides L L, Bae J H, Lee C K (1987). Separation Science and Technology. 22(2-3): 581-617.

5. Singh H, Gupta C K (2000). Miner Proc Extr Metal IRev. 21(1-5): 307-349. 